\title{
IMPROVING EFFICIENCY OF AGRICULTURAL MACHINERY EXPLOITATION AS FACTOR OF OPTIMIZATION USE OF AGRICULTURAL LAND
}

\author{
Elena Yanzina ${ }^{1}$, Vladimir Yanzin ${ }^{1}$, Oksana Mamai ${ }^{1}$, Velta Parsova ${ }^{2}$ \\ ${ }^{1}$ Samara State Agricultural Academy, Russia; \\ ${ }^{2}$ Latvia University of Life Sciences and Technologies, Latvia \\ yanzinaev@mail.ru,yavm@mail.ru,mamai_ov@ssaa.ru,velta@parsova.lv
}

\begin{abstract}
Improving the efficiency of agricultural land use depends primarily on the return on investment and rational use of resources. Agricultural machinery (tractors, aggregates, machines, etc.) is one of the important resources. The use of agricultural tractors in conditions of high air dustiness leads to the ingress of abrasive particles into the internal cavities of the transmission, which causes increased wear of parts and impairs the performance properties of transmission oil. This process is mainly due to transmission gas exchange with the environment, occurring with insufficient tightness of power transmission aggregates. Studies were conducted to determine the magnitude of transmission gas transmission, changes in the tightness of transmission cavities, as well as the accumulation of mechanical impurities and iron in the transmission oil during the operation of the tractor. The BELARUS-80.1 tractor was used as an object of the study. Studies were carried out both in bench and in operational conditions. To assess the tightness of tractor transmissions, an installation was developed that allows determining the qualitative and quantitative indicators of tightness. Based on the research, it was found that the change in the temperature and air volume contained in the transmission cavity has the greatest effect on the gas exchange rate. So, when the transmission temperature of the tractor BELARUS- 80.1 changes by $1^{\circ} \mathrm{C}$, the transmission gas exchange with the environment is $0.5-0.6 \mathrm{dm}^{3}$. It was established that, while improving the tightness of the transmission by $10-15 \%$, the wear of parts, estimated by the change in the mass fraction of iron in oil, decreased by $15-17 \%$.
\end{abstract}

Keywords: machinery, efficiency, tractor, transmission, tightness.

\section{Introduction}

Land resources are the main means of production in agriculture [1]. They influence the yield of agricultural crops, productivity of land, nutritional value of feed, quality of the products produced, and ultimately the result of the activities of agricultural enterprises [2]. Effective use of land resources in agricultural production is impossible without taking into account objective and reliable information about the qualitative condition of the soil and level of its pollution [3].

Agricultural machinery is used in crop production for the cultivation, harvesting and processing of crops. The variety of mechanisms used is very large. The impact of the agricultural technology on the environment is in soil compaction, disruption of its structure during processing, destruction of soilforming microorganisms and various invertebrates (earthworms), technological losses of soil, pollution of soil, water and air with fuels and lubricants and waste engine work, the destruction of animals and birds. High levels of machine reliability [4], as well as reduction of their negative impact on the soil and the environment can be ensured only with their proper operation and high quality of maintenance and repair, using effective methods and means of reliability control [5]. The study of the reliability of modern agricultural tractors shows that $20-40 \%$ of failures are accounted for by transmission units [6]. Numerous studies have established that the main type of wear of transmission parts of agricultural tractors is abrasive wear $[7 ; 8]$.

The operation of tractors in the performance of various agricultural operations takes place in a dusty environment, when the smallest dust particles under the influence of tractor propulsion, agricultural tools and ascending flows are suspended in air [9]. The dustiness of the ambient air is a variable quantity, depending on many factors: the state of the soil, speed of movement of the tractor unit, design of the undercarriage of the tractor, the speed and direction of the wind, etc. The temperature inside the transmission units at steady state is determined by the dynamic equilibrium between the amount of the heat released in the private mechanisms and the amount of the heat abstracted to the external environment [10]. During the operation of the tractor, a continuous change in the temperature mode occurs, due to the change in the load-speed modes of the unit, environmental conditions, technical condition of the unit, the organization of work, etc. Therefore, for the temperature of the transmission oil in a running transmission, although it tends to some steady-state value, however, as a result of the above conditions, its constant change occurs. 
A change in the temperature of the transmission oil inevitably causes a change in the volume of air contained in the transmission cavity, as well as a change in the intrinsic volume, the volume of parts and the transmission housing. This causes gas exchange of the internal transmission cavity with the environment [11]. The process of transmission gas exchange, which ultimately causes the transmission oil to become contaminated with abrasive particles, is a consequence of the poor tightness of the tractor's power transmission cavities. For tractors of various brands, more than $50 \%$ of the total number of faults are associated with unsatisfactory tightness of connections [12]. In addition, the poor tightness of the transmission cavities increases the consumption of gear oil due to its leakage, which in turn has a negative impact on the ecology in general and on land resources in particular.

The purpose of the study is to determine the magnitude of transmission gas exchange, changes in the tightness of transmission cavities, as well as the accumulation of mechanical impurities and iron in transmission oil during the operation of the tractor.

To achieve this goal, the following tasks were solved:

- assess the influence of the temperature of the transmission oil on the magnitude of the gas exchange of the tractor's transmission;

- determine the change in the tightness of the transmission cavities during operation;

- determine the dynamics of the accumulation of mechanical impurities and iron in gear oil, depending on the tightness of the transmission.

\section{Materials and methods}

The object of the study was the process of contamination of transmission oil with mechanical impurities and its connection with the tightness of the tractor transmission. Experimental studies were conducted in the laboratories of the Samara State Agricultural Academy, and operational in the conditions of agricultural enterprises of the Samara region. The BELARUS-80.1 universal tilled tractor was chosen as the object of the research. Tractors of this brand are widely used in agricultural work in the Volga region, and their transmission is typical for mechanical transmissions of modern high-speed tractors. In addition, transmissions of BELARUS tractors have a large amount of free space not occupied by parts and oil, which causes an increased gas exchange of the transmission cavity with the environment.

The study of the process of gas exchange between the transmission of the tractor and the environment was carried out on a stand with running drums. During the tests, real operation modes were simulated (temperature and load). Determination of transmission gas exchange was carried out using a specially manufactured unit. Measurement of the temperatures of oil and air in the transmission cavities was carried out using an electronic thermometer TET-2, the measurement accuracy of which is $0.2^{\circ} \mathrm{C}$.

The determination of the tightness of the tractor transmissions was carried out by the developed installation, which allows not only to show how leaky the transmission is, but also to indicate the places of depressurization. A quantitative assessment of the tightness was carried out with the diameter of an equivalent hole, which replaces all the leaks of transmission units. In this case, a calibration chart was used for the dependence of the diameter of an equivalent hole on the pressure generated by the blower.

In order to build a calibration graph, special experiments were carried out, which made it possible to identify the relationship between the pressure created by the blower and the diameter of the orifice in the diaphragm at the exit of the blower. Calibration chart showed that, when the outlet is completely closed, the blower creates a pressure of $11.8 \mathrm{kPa}$. With an increase in the diameter of the hole in the diaphragm from 1.0 to $20.0 \mathrm{~mm}$, the pressure decreased from 11.75 to $2.64 \mathrm{kPa}$. Thus, by measuring the pressure that a blower creates in a real transmission using this graph, it is possible to estimate the tightness with the diameter of an equivalent hole.

It should be noted that with the help of this installation it is possible to determine the amount of depressurization of transmission sealing devices. To do this, it is necessary to determine the ratio of overpressure that occurs in the transmission, when measuring the tightness and pressure created by the 
blower with the outlet completely closed. Knowing the ratio of these pressures can determine the coefficient of depressurization of the transmission (1).

$$
\eta=1-\frac{P}{P_{\max }},
$$

where $P$ - overpressure created in the transmission, when measuring the tightness, $\mathrm{Pa}$; $P_{\max }-$ maximum pressure that the blower can create with the outlet completely closed, $\mathrm{Pa}$.

Analysis of the equation shows that the lower the value of the depressurization factor $(\eta \rightarrow 0)$, the better the technical condition of the sealing devices and, conversely, the value of the coefficient close to one indicates a greater amount of depressurization of the transmission.

To determine the effect of transmission tightness on transmission oil pollution and abrasive wear of parts, field tests of tractors were carried out. As objects of the research, 20 capitally repaired tractors BELARUS-80.1 were taken. The method of the operational tests provided for the determination of the tightness of tractors with a frequency of 240-260 tractor hours with simultaneous sampling of transmission oil. Transmissions were refueled with oil SAE 80W-90 API GL-2. Tractors performed various agricultural works in agricultural enterprises of the Samara region.

In order to check the efficiency and determine the impact of the quality of cleaning the air entering the transmission on the degree of oil contamination, 10 tractors were equipped with experienced air vents installed on the gearbox fill plug, and 10 other tractors worked with air vents of the factory design and installation site. During the tests, the oil level was monitored. For the entire period of the tests in the transmission of tractors, oil was not added. During the tests, the resistance of the experienced breathers was monitored and their visual inspection was carried out.

Selected samples of the oil were subjected to laboratory analysis according to the following indicators:

- content of mechanical impurities (combustible and non-combustible);

- iron content in oil.

Processing of the test data is performed in the standard MS Office Excel application package.

\section{Results and discussion}

In determining the influence of the temperature of transmission oil on the magnitude of the gas exchange of the tractor's transmission, it was found that the thermal conditions and gas exchange depend on numerous factors. The excess temperature of the oil in the volume relative to the ambient temperature is within $60 \ldots 80^{\circ} \mathrm{C}$ and stabilizes after $4 \ldots 5$ hours of continuous operation with a given load. However, under actual operating conditions, there is a continuous change in the temperature of the oil. At the same time, the intensity of change in the oil temperature is within $0.02 \ldots 2.2^{\circ} \mathrm{C} \cdot \mathrm{min}^{-1}$ and above. This process causes the gas exchange of the internal cavity of the transmission with the environment, the magnitude of which for the transmission of the BELARUS-80.1 tractor is $0.5 \ldots 0.6 \mathrm{dm}^{3}$ per degree Celsius, and its speed is $0.25 \ldots 0.275 \mathrm{dm}^{3} \cdot \mathrm{min}^{-1}$ and above in the conditions of unsteady transmission mode.

Using the technique of quantifying the tightness with the diameter of an equivalent hole, as well as a calibration chart characterizing the dependence of the diameter of the equivalent hole on the generated pressure, measurements were taken of the tightness of tractor transmissions both in the factory version and after major repairs.

It is established that the tightness of transmissions $\left(d_{e}\right)$ of new tractors (operating time $50 \ldots .260$ operating hours) is $d_{e}=0.5 \ldots 2.4 \mathrm{~mm}$. During operation, this figure increases and, by the time it reaches 2000 operating hours, with some tractors it reaches $d_{e}=9.2 \ldots 11.4 \mathrm{~mm}$.

In the case of overhauled tractors, transmissions are hermetic in the range from $d_{e}=6.0 \mathrm{~mm}$ to $d_{e}=14.2 \mathrm{~mm}$. This results from the fact that in repairing old reinforced cuffs (stuffing boxes) are not replaced with new ones. In addition, for the manufacture of gaskets detachable joints the materials recommended by the repair technology are not applied, modern sealing pastes and special sealants are not used. There is insufficient control over the quality of fasteners and the moment of their tightening. 
After determining the places of depressurization, work was done to improve the tightness of transmissions (tightening fasteners, replacing gaskets, etc.), with the result that the tightness improved and amounted to $d_{e}=6.0 \ldots 9.3 \mathrm{~mm}$. Observations on these tractors in the course of ordinary operation showed that with an increase in the operating time of tractors, the tightness of transmissions deteriorates to the operating time of $980 \ldots 1400$ operating hours by an average of $14 \ldots 27 \%$.

In addition, it was found that transmissions of overhauled tractors have, after repair, a depressurization factor ranging from 0.08 to 0.15 and during operation this figure increases to $0.19 \ldots 0.69$. This is convincing that during operation periodic monitoring of the state of the sealing devices and transmission breather is necessary, followed by bringing the leak-tightness indicators to the standard value. To reduce contamination of transmission oil with abrasive particles, it is necessary that the transmission gas exchange be carried out only through a breather having a minimum transmission coefficient, low resistance and located in the zone of least dust. This is possible only with good tightness of the tractor transmission cavities.

Tests of various breathers in the dust chamber showed that an experienced breather has significant advantages compared with the BELARUS-80.1 tractor transmission breather. The experienced breather has $30 \ldots 34$ times less resistance, 56...74 times reduces the skip coefficient compared with the tractor serial breather. In addition, an experienced breather has the property of self-cleaning when changing the direction of the air flow. The self-cleaning coefficient is 0.6...0.7 on the studied modes.

The limited scope of this article does not allow to present all the operational test data of the BELARUS-80.1 tractors, but their mathematical processing showed that the mass fraction of abrasive in transmission oil $\left(\gamma_{e}\right)$ depends on the tightness of the transmission $\left(d_{e}\right)$ (Fig. 1), and their linear dependence is observed.

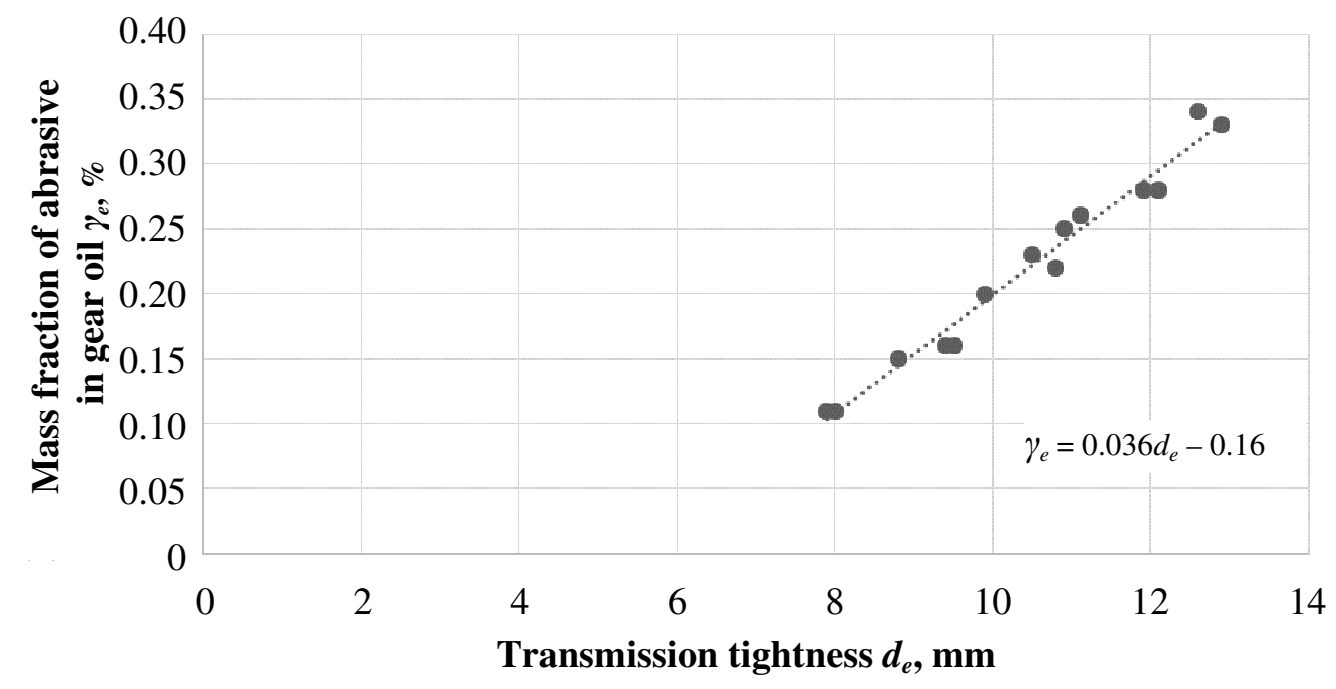

Fig. 1. Dependence of abrasive content in oil on tightness of transmission

During the period of testing tractors with a duration of $970 \ldots 1340$ operating hours, the mass fraction of abrasive in oil in transmissions having an average tightness over the test period $d_{e}=7 \ldots 8$ $\mathrm{mm}$ amounted to $0.109 \ldots 0.126 \%$ at the end of the tests, and in transmissions with $d_{e}=12 \ldots 13 \mathrm{~mm}$ respectively $0.286 \ldots 0.355 \%$. It should be noted that in transmissions with experienced air vents the mass fraction of abrasive in oil is $12 . .29 \%$ lower than in serial transmissions. Thus, in order for the mass fraction of abrasive particles in gear oil to not exceed the maximum permissible value of $0.1 \%$, it is necessary to ensure the total value of transmission leakages not more than $d_{e}=7 \ldots 8 \mathrm{~mm}$ (Fig. 1). This parameter should be maintained during the entire service life of the tractor, periodically checking tightness during maintenance and eliminating any leakages that occur in the transmission.

The tests shown that in proportion to the increase in abrasive in oil, due to insufficient tightness, an increase in the mass fraction of iron is observed as a result of wear of transmission parts. It has been established that with the tightness of transmissions of tractors BELARUS-80.1. $d_{e}=7 \ldots 7.5 \mathrm{~mm}$ wear of parts was $6.8 \ldots 7.4 \cdot 10^{-2} \%$, while at $d_{e}=11 \ldots 12 \mathrm{~mm}$, the mass fraction of iron in oil reached $15.9 \ldots 20.1 \cdot 10^{-2} \%$. 
Thus, as a result of long-term performance tests, a significant effect of transmission tightness on the wear of its parts was revealed. With the improvement of tightness by $10 \ldots 15 \%$, the wear of parts, estimated by the change in the mass fraction of iron in oil, decreased by $15 \ldots 17 \%$. It was established that if the tightness of the transmission, estimated by the diameter of the equivalent hole, does not exceed $7 \ldots 8 \mathrm{~mm}$, then the abrasive content in the oil before its change will not exceed the maximum permissible value $0.1 \%$.

\section{Conclusions}

1. Effective use of land resources in agricultural production is impossible without taking into account objective and reliable information about the qualitative condition of the soil and level of its pollution.

2. High level of machine reliability, as well as reduction of its negative impact on the soil and the environment can be ensured only with their proper operation and high quality of maintenance and repair, using effective methods and means of reliability control.

3. The study of the reliability of modern agricultural tractors showed that 20 to $40 \%$ of the failures accounted for the share of transmission units.

4. As a result of long-term operational tests, a significant effect of transmission tightness on the wear of its parts was revealed, which generally affects the efficiency of use of agricultural equipment and reduces the negative impact on the environment.

5. During operation, periodic monitoring of the state of the sealing devices and the transmission breather is required, followed by bringing the tightness indicators to the standard value. Therefore, the optimal use of agricultural land and reducing the negative impact on the environment is possible only with proper and careless operation of agricultural equipment.

\section{References}

[1] Carlson M., Browne D., Callaghan C. Application of land-use simulation to protected area selection for efficient avoidance of biodiversity loss in Canada's western boreal region. Land use policy, vol. 82, 2019, pp. 821-831.

[2] Parsova V., Mamai O., Zudilin S. Assessment of efficiency of use of agricultural land: example of Samara region. Proceedings of 17th International Scientific Conference "Engineering for Rural Development", May 23-25, 2018, Jelgava, Latvia, pp. 624-631.

[3] Wilson C.O., Liang B.Q., Rose S.J. Projecting future land use/land cover by integrating drivers and plan prescriptions: the case for watershed applications. Giscience \& Remote sensing, vol. 56 (4), 2019, pp. 511-535.

[4] Amy I., Letizia C., Ilinca T. Thinking ahead of the tractor: driver safety and situation awareness. Journal of agromedicine, 2019, pp. 1-10.

[5] Kopiks N., Viesturs D., Rucins A. Changes in technical support on farms of Latvia. Proceedings of 17th International Scientific Conference "Engineering for Rural Development", May 23-25, 2018, Jelgava, Latvia, pp. 246-249.

[6] Спицын И.А., Ардеев Е.Н., Орехов А.А. Улучшаем герметичность - повышаем ресурс (We improve tightness - we increase a resource). Country Mechanic, vol. 4, 2006, pp. 32-41. (In Russian).

[7] Орехов, А. Влияние эксплуатационных факторов на абразивное изнашивание зубчатых передач тракторных трансмиссий (The influence of operational factors on the abrasive wear gears of tractor transmissions). Abstracts of young scientists, Penza, 1998, pp. 107-108. (In Russian).

[8] Berjoza D., Pirs V., Jurgena I., Laceklis-Bertmanis J.Energy use efficiency of electric automobile depending on transmission gear ratio. Proceedings of 17th International Scientific Conference "Engineering for Rural Development”, May 23-25, 2018, Jelgava, Latvia, pp. 2023-2029.

[9] Janulevicius A., Sarauskis E., Cipliene A. Estimation of farm tractor performance as a function of time efficiency during ploughing in fields of different sizes. Biosystems engineering, vol. 179, 2019, pp. 80-93. 
[10]Lee J.W., Kim J.S., Kim K.U. Computer simulations to maximise fuel efficiency and work performance of agricultural tractors in rotovating and ploughing operations. Biosystems engineering, vol. 142, 2016, pp. 1-11.

[11] Янзин В.М. Показатели, характеризующие герметичность трансмиссии и их определение при техническом обслуживании трактора (Indicators characterizing the tightness of the transmission and their determination during tractor maintenance). Collection of scientific papers "Resource-saving methods of using agricultural machinery", Ulyanovsk, 1990, pp. 19-22 (In Russian).

[12]Бондарева Г.И. Герметизация неподвижных фланцевых соединений силиконовыми герметиками при ремонте сельскохозяйственной техники (Sealing of fixed flange joints with silicone sealants when repairing agricultural equipment). Moscow, 20 p. (In Russian). 